\title{
Mathematical Model Predicts the Elastic Behavior of Composite Materials
}

\author{
Zoroastro de Miranda Boari $^{\mathrm{a}, \mathrm{d}} *$, Waldemar Alfredo Monteiro ${ }^{\mathrm{b}, \mathrm{d}}$, \\ Carlos Alexandre de Jesus Miranda ${ }^{\mathrm{c}, \mathrm{d}}$ \\ ${ }^{\mathrm{a}}$ Center for Materials Science and Technology, Ipen-Cnen, São Paulo - SP \\ ${ }^{\mathrm{b}}$ Materials Science and Technology Center, Ipen-Cnen, São Paulo and Faculty of Biological, \\ Pure And Experimental Sciences, Mackenzie Presbyterian University, São Paulo - SP \\ 'Department of Structural Mechanics, Nuclear Engineering, Ipen-Cnen, São Paulo - SP \\ ${ }^{\mathrm{d}}$ Instituto de Pesquisas Energéticas e Nucleares \\ Av. Lineu Prestes, 2242 Cidade Universitária, 05508-900 São Paulo - SP, Brazil
}

Received: October 29, 2003; Revised: February 3, 2005

\begin{abstract}
Several studies have found that the non-uniform distribution of reinforcing elements in a composite material can markedly influence its characteristics of elastic and plastic deformation and that a composite's overall response is influenced by the physical and geometrical properties of its reinforcing phases. The finite element method, Eshelby's method and dislocation mechanisms are usually employed in formulating a composite's constitutive response. This paper discusses a composite material containing $\mathrm{SiC}$ particles in an aluminum matrix. The purpose of this study was to find the correlation between a composite material's particle distribution and its resistance, and to come up with a mathematical model to predict the material's elastic behavior. The proposed formulation was applied to establish the thermal stress field in the aluminum-SiC composite resulting from its fabrication process, whereby the mixture is prepared at $600{ }^{\circ} \mathrm{C}$ and the composite material is used at room temperature. The analytical results, which are presented as stress probabilities, were obtained from the mathematical model proposed herein. These results were compared with the numerical ones obtained by the FEM method. A comparison of the results of the two methods, analytical and numerical, reveals very similar average thermal stress values. It is also shown that Maxwell-Boltzmann's distribution law can be applied to identify the correlation between the material's particle distribution and its resistance, using Eshelby's thermal stresses.
\end{abstract}

Keywords: metal - matrix composites (MMCs), particle - reinforced composites, modelling

\section{Introduction}

The effective reinforcement of composite materials depends on the distribution of $\mathrm{SiC}$ particles in the aluminum matrix. This distribution affects both the elastic and the plastic behaviors of such composites, albeit in different ways. Also worth keeping in mind is the fact that the greater the number of particle clusters in a composite material, the lower its resistance. Hence, the composite's resistance is greatest when its constituent elements are uniformly distributed in the matrix. Mathematical models that evaluate the dependence of a composite's resistance on its particle distribution are crucial for predicting the composite's mechanical properties.

We discuss this dependence and propose a mathematical model to predict the elastic behavior of a composite material consisting of $\mathrm{SiC}$ particles in an aluminum matrix. The model is based on Maxwell-Boltzmann's distribution law to correlate the $\mathrm{SiC}$ distribution to the composite's resistance, using Eshelby's stress. The results of this model were confirmed by the finite elements method (FEM).

\section{Probability of a Distribution}

This work involved an adjustment of the observations of Beiser ${ }^{1}$ and Reif ${ }^{2}$ about statistical mechanics, which were then applied to investigate the most probable behavior of particle distribution. According to this modeling method, the state of a particle system is completely specified at a given instant if the position and potential energy (rather than the kinetic energy) of each particle are known. This modeling assumes that the aluminum matrix is divided into
$\mathrm{K}$ cells, whose areas are $\mathrm{a}_{1}, \mathrm{a}_{2} \mathrm{a}_{3}, \ldots, \mathrm{a}_{\mathrm{k}}$. The SiC particles are tossed randomly into the matrix, without favoring any particular part, and the number of particles that have fallen in each cell is recorded. After repeating this procedure many times, one finds that the particles tend to fall into a particular distribution pattern among the various cells more frequently than any other perceptible pattern. This, then, is the most probable particle distribution, and the number of particles in each cell is proportional to the cell's size. This paper presents a study of the most probable distribution and of the corresponding stress distribution.

\section{Maxwell-Boltzmann Statistics}

According to Beiser ${ }^{1}$, Maxwell-Boltzmann's distribution law can be expressed as follows:

$$
n_{\mathrm{i}}=g_{i} e^{-\alpha} e^{-\beta u_{i}}
$$

The most probable number of particles in any cell is $n_{i}$ and the total number of particles is $\mathrm{N}$. The a priori probability $\mathrm{g}_{\mathrm{i}}$ of a particle falling into the ith cell is the ratio of its $\mathrm{a}_{\mathrm{i}}$ area and the total $\mathrm{A}$ area of the entire matrix. The total a priori probability is 1 . The $n_{i}$ independent $\alpha$ and $\beta$ are called Lagrange multipliers. The "Partition Function", known as $e^{-\beta u_{i}}$, shows the distribution of particles in the various potential energy levels.

Beiser ${ }^{1}$ used Maxwell-Boltzmann's distribution law to divide the 
kinetic energy among the molecules. In our modeling, the kinetic energy is transformed into elastic potential energy ${ }^{3}$. The question is: How is the elastic potential energy distributed among the various energy levels produced by $\mathrm{N}$ particles?

This elastic potential energy is caused by the stress produced during cooling due to the differences in the coefficients of thermal expansion (CTE) of the $\mathrm{SiC}$ and the aluminum.

The matrix's mean stress is used to find the approximate solution of this distribution law by Eshelby's method, as shown by several authors ${ }^{4-8}$.

$\alpha$ and $\beta$ are obtained by the method described by Beiser ${ }^{1}$, while the matrix's mean stress described by Clyne et al. ${ }^{4}$ is used in the model to determine Maxwell-Boltzmann's modified distribution law, which indicates the partition of stress in the particles according to their distribution in the aluminum matrix. To this end, consider a continuous distribution of energies, rather than the discrete set $u_{l}$, $u_{2}, \ldots, u_{\mathrm{k}}$, so that Equation 1 becomes

$n(u) d u=g e^{-\alpha} e^{-\beta u} d u$

The number of particles in which energies lie between $u$ and $u+$ $d u$ is interpreted as $n(u) d u$, where $\mathrm{u}$ is the elastic potential energy.

In terms of stress, Equation 2 can now be written as:

$$
n(\sigma) d \sigma=g e^{-\alpha} e^{-\beta \frac{\sigma^{2}}{2 E}} d \sigma
$$

with $\mathrm{E}$ as Young's modulus.

The Beiser ${ }^{1}$ development is used to find $\mathrm{e}^{-\alpha}$ and $\beta$.

Thus,

$n(\sigma) d \sigma=4 \pi N\left(\frac{\beta}{2 E \pi}\right)^{3 / 2} \sigma^{2} e^{-\beta^{\frac{\sigma^{2}}{22}}} d \sigma$

The total energy $U$ of the set of particles is used to find $\beta$, so that

$U=\frac{3}{2} \frac{N}{\beta}$

The total energy $U$ can also be written as:

$$
U=u N
$$

The elastic potential energy $u$ is a function of the matrix's mean stress $^{3,4}$, which determines the approximate solution of the distribution law.

$$
\frac{3}{2} \frac{N}{\beta}=\frac{f C_{M}\left[(\mathrm{~S}-\mathrm{I}) \varepsilon_{\mathrm{k}}^{*}\right]^{2}}{2} N
$$

$\varepsilon_{\mathrm{kl}}^{*}$ is called the eigenstrain ${ }^{4,5}, \boldsymbol{S}$ is the Eshelby tensor, $\boldsymbol{I}$ is the identity matrix and $f$ is the volume fraction of particles or inclusions.

Hence,

$$
\beta=\frac{3}{f C_{M}\left[(\mathrm{~S}-\mathrm{I}) \varepsilon_{\mathrm{k1}}^{*}\right]^{2}}
$$

So, Equation 4 becomes the modified Maxwell-Boltzmann distribution law:

$$
n(\sigma)=4 \pi N\left(\frac{3}{2 C_{M} K \pi}\right)^{3 / 2} \sigma^{2} e^{-\frac{3 \sigma^{2}}{K 2 C_{M}}}
$$

and

$$
K=f C_{M}\left[(\mathrm{~S}-\mathrm{I}) \varepsilon_{\mathrm{kl}}^{*}\right]^{2}
$$

or

$$
\begin{aligned}
& K=f C_{M}\left\{( \mathrm { S } - \mathrm { I } ) \left\{\left(\mathrm{C}_{\mathrm{M}}-\mathrm{C}_{\mathrm{I}}\right)[\mathrm{S}-\mathrm{f}(\mathrm{S}-\mathrm{I})]-\right.\right. \\
& \left.\left.\mathrm{C}_{\mathrm{M}}\right\}^{-1} \mathrm{C}_{\mathrm{I}}\left(\alpha_{\mathrm{I}}-\alpha_{\mathrm{M}}\right) \Delta \mathrm{T}\right\}^{2}
\end{aligned}
$$

$\mathrm{C}_{\mathrm{M}}$ and $\mathrm{C}_{\mathrm{I}}$ are called the matrix and particle elastic tensor components, respectively, while $\alpha_{M}$ and $\alpha_{1}$ are CTE matrix and particle tensors, respectively, and $\Delta T$ is the temperature change.

$$
\begin{aligned}
& \mathrm{C}_{\mathrm{Mii}}=\mathrm{E}_{\mathrm{M}}\left(1-v_{\mathrm{M}}\right) /\left(1-2 v_{\mathrm{M}}\right)\left(1+v_{\mathrm{M}}\right) \\
& \mathrm{C}_{\mathrm{Mij}}=\mathrm{E}_{\mathrm{M}} v_{\mathrm{M}} /\left(1-2 v_{\mathrm{M}}\right)\left(1+v_{\mathrm{M}}\right) \\
& \mathrm{C}_{\mathrm{M} 44}=\mathrm{E}_{\mathrm{M}} / 2\left(1+v_{\mathrm{M}}\right) \\
& \mathrm{C}_{\mathrm{Iii}}=\mathrm{E}_{\mathrm{I}}\left(1-v_{\mathrm{I}}\right) /\left(1-2 v_{\mathrm{I}}\right)\left(1+v_{\mathrm{I}}\right) \\
& \mathrm{C}_{\mathrm{Iij}}=\mathrm{E}_{\mathrm{I}} \mathrm{v}_{\mathrm{I}} /\left(1-2 v_{\mathrm{I}}\right)\left(1+v_{\mathrm{I}}\right) \\
& \mathrm{C}_{\mathrm{I} 44}=\mathrm{E}_{\mathrm{I}} / 2\left(1+v_{\mathrm{I}}\right)
\end{aligned}
$$

Equation 9 represents the stress distribution function acting in the composite material with the random spatial distribution of $\mathrm{SiC}$ particles in the aluminum matrix.

It is useful to consider $\boldsymbol{L}$ as a constant that can be used to facilitate the derivative of Equation 9

$$
L=4 \pi N\left(\frac{3}{2 C_{M} K \pi}\right)^{3 / 2}
$$

This $\boldsymbol{L}$ must be replaced in Equation 9

$n(\sigma)=L \sigma^{2} e^{-\frac{3 \sigma^{2}}{2 \kappa C_{M}}}$

\subsection{The most probable stress}

The maximum value will be obtained from the derivative of Equation 14. The most probable stress $\left(\sigma_{p}\right)$ is:

$\sigma_{p}^{2}=\frac{2 f C_{M}^{2}\left\{(S-I)\left\{\left(C_{M}-C_{1}\right)[\mathrm{S}-\mathrm{f}(\mathrm{S}-\mathrm{I})]-\mathrm{C}_{\mathrm{M}}\right\}^{-1} \mathrm{C}_{1}\left(\alpha_{1}-\alpha_{M}\right) \Delta T\right\}^{2}}{3}$

\subsection{Mean stress}

The mean stress is obtained through the formula

$\bar{\sigma}=\frac{\int_{0}^{\infty} \sigma n(\sigma) d \sigma}{N}$

with

$n(\sigma)=\frac{4 N}{\sqrt{\pi}} \frac{1}{\sigma_{p}}\left(\frac{\sigma^{2}}{\sigma_{p}^{2}}\right) e^{-\left(\frac{\sigma^{2}}{\sigma_{p}^{2}}\right)}$

The solution of this equation is

$\bar{\sigma}=1.13 \sigma_{p}($ Mean stress $)$

\subsection{Quadratic mean stress}

The quadratic mean stress is

$\bar{\sigma}^{2}=\frac{\int_{0}^{\infty} \sigma^{2} n(\sigma) d \sigma}{N}$

The solution to this equation is

$$
\overline{\bar{\sigma}}=1.225 \sigma_{p}
$$

\subsection{Materials and simulation method}

The phases in composite materials have significantly dissimilar coefficients of thermal expansion (CTE). The production of composite materials at high temperatures leads to considerably mismatched internal stresses and strains during the cooling process and, in the $\mathrm{Al} / \mathrm{SiC}$ 
system, the fabrication temperature is usually around $600{ }^{\circ} \mathrm{C}$.

Therefore, the most probable stress is determined based on the material's elastic behavior and the following data:

1) Young's modulus of matrix : $E_{M}=73 \mathrm{GPa}$;

2) Young's modulus of $\mathrm{SiC}$ particles: $\mathrm{E}_{\mathrm{I}}=450 \mathrm{GPa}$;

3) CTE of aluminum: $\alpha_{\mathrm{M}}=23.6 \times 10^{-6} \mathrm{C}^{-1}$;

4) CTE of SiC particles: $\alpha_{I}=4 \times 10^{-6} \mathrm{C}^{-1}$;

5) Temperature change: cooling from manufacturing to room temperature or $\Delta \mathrm{T}=-580{ }^{\circ} \mathrm{C}$.

\section{Results}

\subsection{Determination of the most probable stress}

4.1.1. Thermal strain tensor is given by $\varepsilon^{* *}{ }_{\mathrm{kl}}=\left(\alpha_{\mathrm{I}}-\alpha_{\mathrm{M}}\right) \Delta T$

$$
e_{k l}^{* *}=\left[\begin{array}{c}
0.011368 \\
0.011368 \\
0.011368 \\
0 \\
0 \\
0
\end{array}\right]
$$

4.1.2. The elastic constant tensor of the aluminum matrix is given by

$$
C_{M}=\left[\begin{array}{cccccc}
10.8160 & 5.3273 & 5.3273 & 0 & 0 & 0 \\
5.3273 & 10.8160 & 5.3273 & 0 & 0 & 0 \\
5.3273 & 5.3273 & 10.8160 & 0 & 0 & 0 \\
0 & 0 & 0 & 2.7443 & 0 & 0 \\
0 & 0 & 0 & 0 & 2.7443 & 0 \\
0 & 0 & 0 & 0 & 0 & 2.7443
\end{array}\right] x 10^{1 \mathrm{C}}
$$

4.1.3. The elastic constant tensor of the inclusion is

$$
C_{I}=\left[\begin{array}{cccccc}
48.3700 & 9.9100 & 9.9100 & 0 & 0 & 0 \\
9.9100 & 48.3700 & 9.9100 & 0 & 0 & 0 \\
9.9100 & 9.9100 & 48.3700 & 0 & 0 & 0 \\
0 & 0 & 0 & 19.2300 & 0 & 0 \\
0 & 0 & 0 & 0 & 19.2300 & 0 \\
0 & 0 & 0 & 0 & 0 & 19.2300
\end{array}\right] x 10^{10}
$$

\subsubsection{Eshelby's tensor related to spherical inclusion is}

$$
S=\left[\begin{array}{cccccc}
0.53234 & 0.06468 & 0.06468 & 0 & 0 & 0 \\
0.06468 & 0.53234 & 0.06468 & 0 & 0 & 0 \\
0.06468 & 0.06468 & 0.53234 & 0 & 0 & 0 \\
0 & 0 & 0 & 0.23383 & 0 & 0 \\
0 & 0 & 0 & 0 & 0.23383 & 0 \\
0 & 0 & 0 & 0 & 0 & 0.23383
\end{array}\right]
$$

The following volume fractions were used for the calculations: $17.9 \%, 24.4 \%, 31 \%$ and $35.2 \%$. Table 1 lists the most probable stress $\left(\sigma_{p}\right)$, mean stress $(\bar{\sigma})$ and quadratic mean stress $(\overline{\bar{\sigma}})$ for spherical particles, considering the volume fractions.

\section{Discussion}

Twenty-four simulations were done using the finite elements method with different particle distributions and volume fractions. All the results were compatible with the mathematical model. Four of the thermal stress distributions results were selected and are shown in this paper for the aforementioned volume fractions.

Figures 1, 3, 5 and 7 clearly show that the thermal stress distribution graphs for volume fractions of $17.9 \%, 24.4 \%, 31 \%$ and $35.2 \%$ coincide with the range of stresses obtained by FEM simulations, as shown in Figures 2, 4, 6 and 8 for the elastic stress. These figures illustrate the coherence of the results.

Table 1. Results obtained from the most probable stress, mean stress and quadratic mean stress equations, using the mathematical model.

\begin{tabular}{cccc}
\hline $\begin{array}{c}\text { Volume } \\
\text { Fraction } \\
f(\%)\end{array}$ & $\begin{array}{c}\text { Most Probable } \\
\text { Stress } \\
\sigma_{p}(\mathrm{MPa})\end{array}$ & $\begin{array}{c}\text { Mean Stress } \\
\bar{\sigma}=1.13 \sigma_{p} \\
(\mathrm{MPa})\end{array}$ & $\begin{array}{c}\text { Quadratic } \\
\text { Mean Stress } \\
\overline{\bar{\sigma}}=1.225 \sigma_{p} \\
(\mathrm{MPa})\end{array}$ \\
\hline 17.9 & 352 & 398 & 432 \\
24.4 & 404 & 456 & 495 \\
31.0 & 447 & 505 & 547 \\
35.2 & 471 & 532 & 577 \\
\hline
\end{tabular}

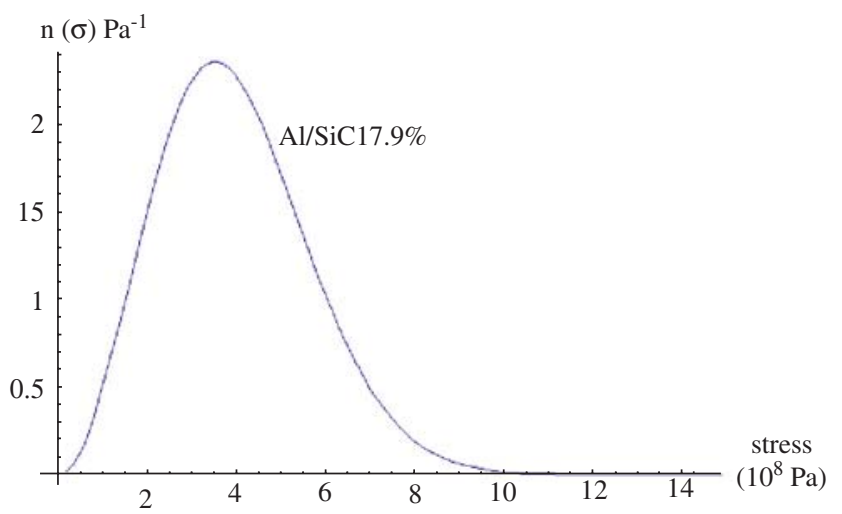

Figure 1. Distribution function of stress for a $17.9 \%$ volume fraction of $\mathrm{SiC}$ in aluminum matrix.

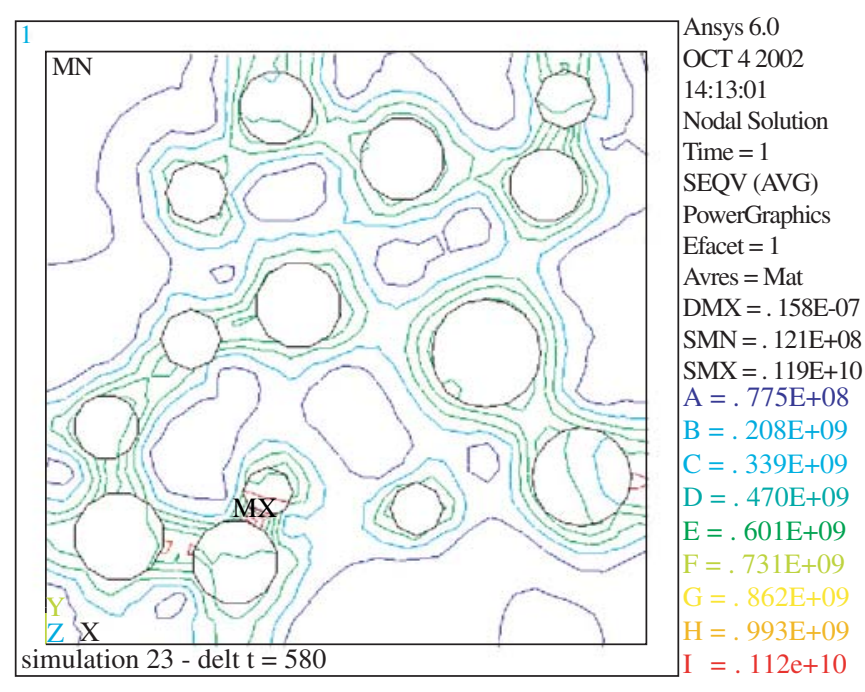

Figure 2. Finite element results (Pa) for a 17.9\% volume fraction of $\mathrm{SiC}$ in aluminum matrix. 


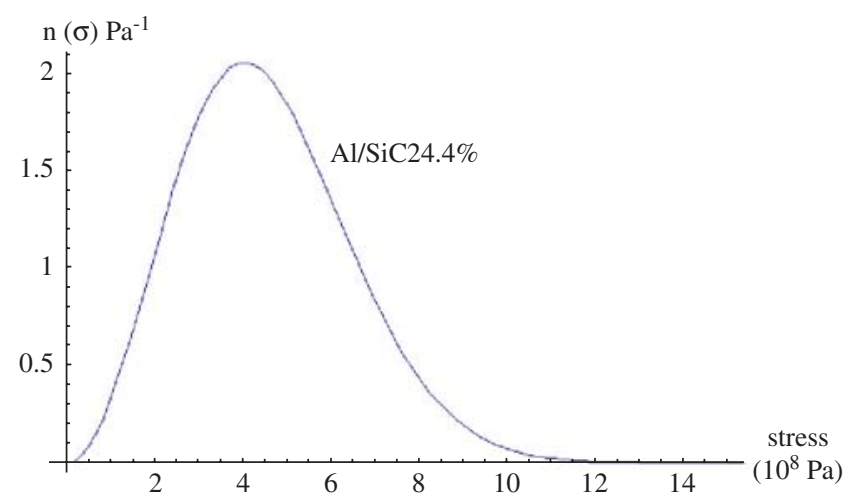

Figure 3. Distribution function of stress for a $24.4 \%$ volume fraction of $\mathrm{SiC}$ in aluminum matrix.

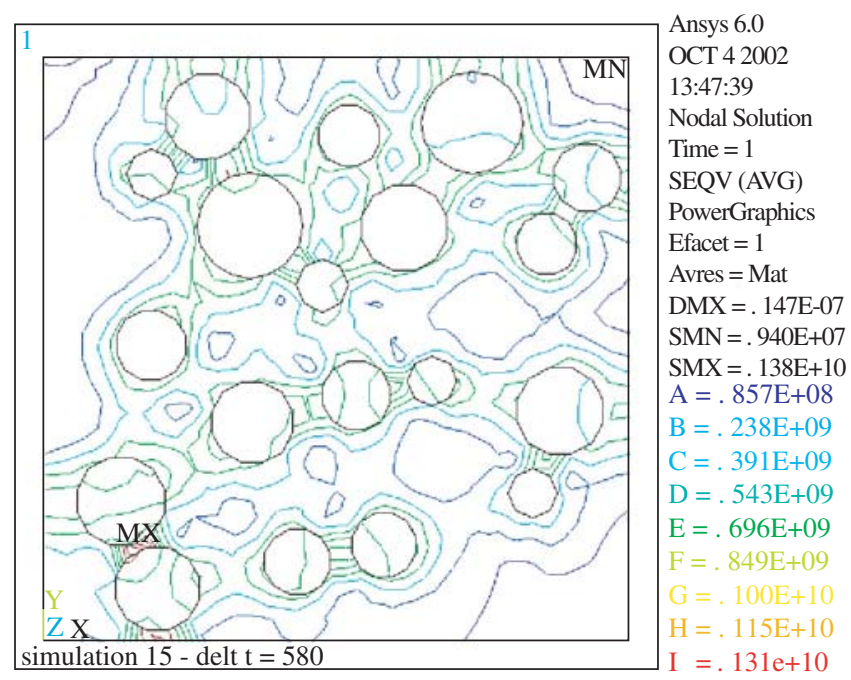

Figure 4. Finite element results $(\mathrm{Pa})$ for a $24.4 \%$ volume fraction of $\mathrm{SiC}$ in aluminum matrix.

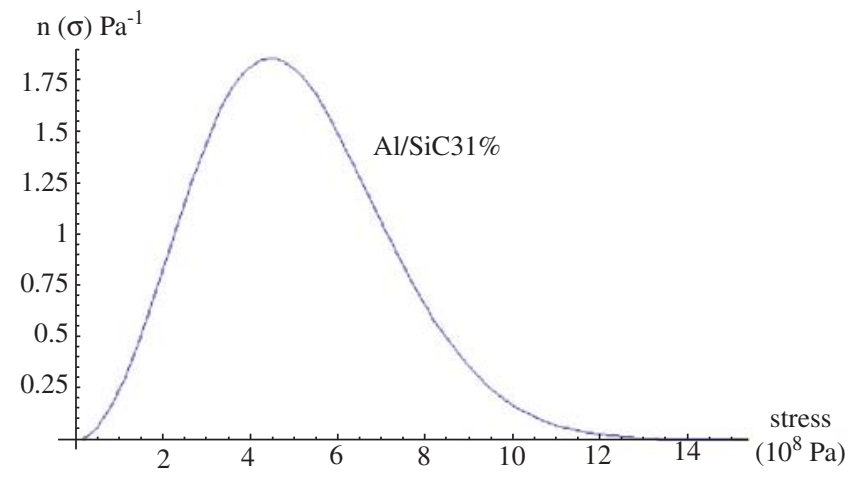

Figure 5. Distribution function of stress for a $31 \%$ volume fraction of $\mathrm{SiC}$ in aluminum matrix.

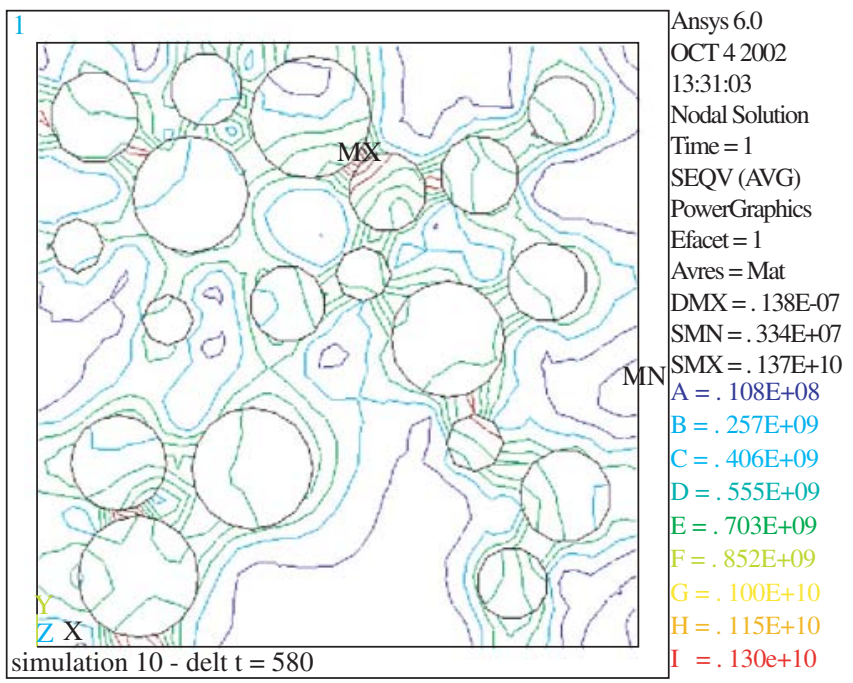

Figure 6. Finite element results $(\mathrm{Pa})$ for a $31 \%$ volume fraction of $\mathrm{SiC}$ in aluminum matrix.

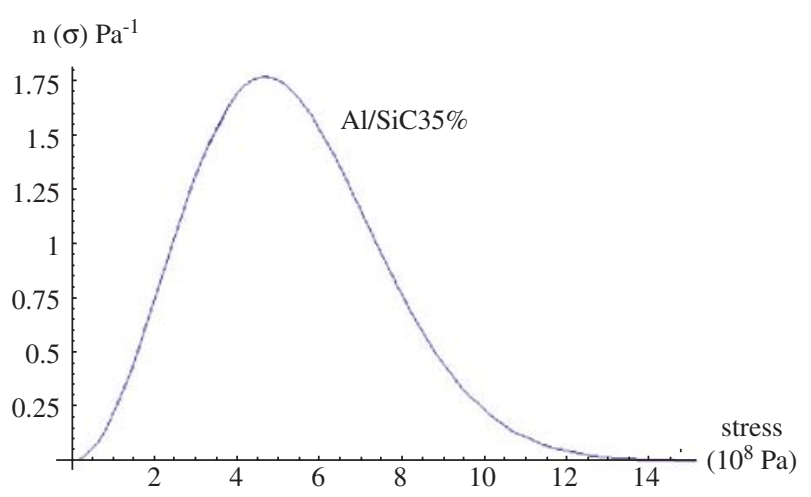

Figure 7. Distribution function of stress for a $35.2 \%$ volume fraction of $\mathrm{SiC}$ in aluminum matrix.

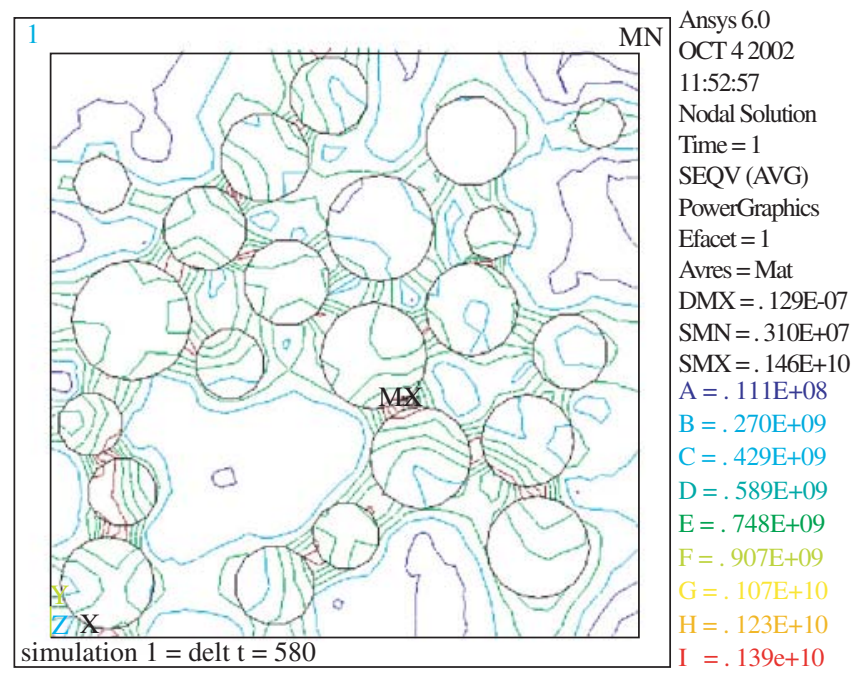

Figure 8. Finite element results $(\mathrm{Pa})$ for a $35.2 \%$ volume fraction of $\mathrm{SiC}$ in aluminum matrix. 
It is logical to assume that the introduction of a high volume fraction of $\mathrm{SiC}$ particles into an $\mathrm{Al}$ matrix should increase the number of clusters considerably and decrease the composite's resistance?. Recent studies have shown that high volume fractions of reinforcement can reduce the matrix's CTE, leading to low CTE composite values ${ }^{10}$. Moreover, the non-uniformity of $\mathrm{SiC}$ particles and aspect ratio exert a strong effect on the local and global damage behavior and stress-strain dependence ${ }^{11}$.

The magnitude of stress and $\mathrm{SiC}$ distribution are determined by the material's thermomechanical processing history. The mechanical behavior of particulate metal-matrix composites is also dependent on the matrix alloy and reinforcement ${ }^{12}$.

Based on the stress distribution graphs obtained through the mathematical model, the area between two stress values is the number of particles per stress unit.

\section{Conclusions}

The mathematical model proposed herein analyzes the elastic response of a two-phase composite as a function of the spatial distribution of the reinforcement. This study led to the following conclusions:

- The non-uniformity of SiC particle distribution strongly affects the stress-strain relation in composite materials. This effect also depends on the volume fraction of the reinforcement. There is a broad consensus on this issue;

- As it stands, the approach presented here indicates a method that considers the clustering effect on thermal stress. This method proved as efficient as the FEM method to estimate thermal stress;

- This paper proposes a mathematical model to obtain the elastic response of composite materials. The factors that control matrix plasticity will be the object of future studies to determine the plastic behavior of composite materials.

\section{References}

1. Beiser A. Concepts of Modern Physics. 2.a ed. Mc Graw-Hill Book Company, Inc.; 1963. p. 235-246.

2. Reif F. Fundamentals of Statistical and Thermal Physics. Physics Series. Singapore: McGraw-Hill International Editions; 1985. p. 262-265; p. 343345 .

3. Boari Z M. Modelo Matemático da Influência da Distribuição de Partículas de SiC nas Tensões Térmicas em Compósitos de Matriz Metálica. [Unpublished D. Phil. thesis]. São Paulo: Universidade de São Paulo, IPEN; 2003. p. 50-75.

4. Clyne T W, Withers P J. An Introduction to Metal Matrix Composites. First ed.. Cambridge: Cambridge University Press; 1993. p. 44-64.

5. Taya M, Arsenault R J. Metal Matrix Composites - Thermomechanical Behavior. First ed.. Pergamon Press; 1989. p 32-35.

6. Withers P J, Stobbs W M, Pedersen O B. The Application of the Eshelby Method of Internal Stress Determination to Short Fiber Metal Matrix Composites. Acta Metall. 1989; 37(11):3061-3084.

7. Taya M, Lulay K E, Lloyd D J. Strengthening of a Particulate Metal Matrix Composite by Quenching. Acta Metall. 1990; 39(1):73-87.

8. Arsenault R J, Taya M. Thermal Residual Stress In Metal Matrix Composite. Acta Metall. 1987; 35(3):651-659.

9. Christman T, Needleman A, Suresh S. An Experimental and Numerical Study of Deformation in Metal-Ceramic Composites. Acta Metall. 1989; 37(11):3029- 3050.

10. Kim B G, Dong S L, Park S D. Effects of Thermal Processing on Thermal Expansion Coefficient of a 50 vol.\% SiCp-Al Composite. Materials Chemistry and Physics. 2001; 72:42-47.

11. Geni M, Kikuchi M. Damage Analysis of Aluminum Matrix Composite Considering Non-uniform Distribution of SiC Particles. Acta Metall. 1998; 46(9):3125-3133.

12. Humphreys F J, Basu A, Djazeb M R. The Microstructure and Strength of Particulate Metal-Matrix Composites. Conference: Metal Matrix Composites - Processing, Microstructure and Properties; 1991; Roskilde, Denmark. Riso National Laboratory - Materials Department; 1991. p. 51-66. 